\title{
Melting Characteristics of a Phase Change Material Mixed with Nano Particles of Cobalt Oxide Bounded in a Trapezoidal Structure
}

\author{
Waris Ali $^{1}$, Asif Ali Shaikh ${ }^{1}$, Feroz Shah ${ }^{1}$ and Sajjad Hussain ${ }^{2,3, *}$ \\ ${ }^{1}$ Department of Basic Sciences and Related Studies, Mehran University of Engineering and Technology, Jamshoro, Pakistan \\ ${ }^{2}$ School of Mechanical and Aerospace Engineering, Nanyang Technological University, Singapore \\ ${ }^{3}$ Department of Mathematics, Govt Postgraduate College Layyah, Punjab, Pakistan \\ *Corresponding Author: Sajjad Hussain. Email: sajjadgut@gmail.com
}

Received: 30 April 2021 Accepted: 29 June 2021

\begin{abstract}
A novel trapezoidal design for storage of heat energy through melting of phase-change material (PCM) is investigated. Latent heat thermal energy storage system (LHTES) is a promising option to diminish mis-match between energy consumption and supply. For this purpose, Paraffin: Rubitherm-35 (RT35) material is successively melted in aluminum structure which is heated from one side and the other sides are kept adiabatic. Melting of PCM is observed experimentally and melt fronts are photographed for various time lengths. The fluid-solid module in COMSOL Multiphysics 5.4 has been utilized. The transient heat conduction with enthalpy function is hired. Simulations are carried out for enhancement of thermal conductivity through addition of nano-entities of cobalt oxide $\mathrm{Co}_{3} \mathrm{O}_{4}$. The melting time is notably reduced with inclusion of nano-entities to enhance thermal conductivity. The time spans for melt start and total melt in case of pure PCM are 375 and 4500 (s) respectively whereas for the nano mix case, these are 150 and 3000 s. Thus 33\% shorter time length is noticed for charging of the PCM trapezoidal matrix with nano entities of $\mathrm{Co}_{3} \mathrm{O}_{4}$ are mixed. The results from simulation and lab observations depict similar patterns and are in quite close comparison.
\end{abstract}

\section{KEYWORDS}

Trapezoidal enclosure; nano entities; heat transfer; phase change material COMSOL multiphysics 5.4; numerical simulation

$\begin{array}{ll}\text { Nomenclature } & \\ U & \text { Velocity } \\ \tau & \text { Stress tensor } \\ \beta & \text { fluid fraction } \\ \mathrm{P} & \text { Pressure } \\ \mathrm{K} & \text { Thermal conductivity } \\ \mathrm{S} & \text { Volumetric heat generation } \\ H & \text { Enthalpy }\end{array}$


$\begin{array}{ll}h . & \text { Sensible enthalpy } \\ T & \text { Temperature } \\ \rho & \text { Density }\end{array}$

\section{Introduction}

Thermal energy can be processed in three forms: latent, sensible and chemical. The LHTES technologies with phase modifying substances have shown significant potential for resolving the problem of heat demand $v s$. supply through intermittent alternative energy methods like solar energy [1,2]. If the heat production exists during the process of transformation, PCMs accumulate a significant amount of heat without growing the temperature. LHTES have been widely used in a variety of technological fields including thermal management for cold storage, heating systems, space heating/cooling, food manufacturing and aircraft defense mechanisms [3,4]. The benefits of LHTES include a higher energy density and a limited collection volume [5]. Recently, Bayon [6] presented a brief review on advanced phase change materials for thermal storage. Furthermore, as opined by Mao et al. [7], the effective expansion of a low-carbon economy has appeared an imperative option for creating a win-win condition of economic implementation and environment conservation across the world. PCMs-type cooling has been promoted as a successful solution because it can capture heat through devices and machines and store it for later application, including heating houses and offices [8]. Basit et al. [9] examined forced convection heat transfer from arrays of prolate particles with aspect ratio of 2.5 and varying volume fractions. PCMs are utilized for a variety of applications due to their multiple benefits such as higher latent heat of fusion, large effective heat, manageable temperature stabilization, and low volume change through process transformation [10,11]. Zsembinszki et al. [12] discussed how to choose apposite PCM for compact energy storage systems implemented in residential buildings, space cooling and heating domestic water. The influence of the high temperature fluid (HTF) inlet conditions on the thermal energy storage (TES) efficiency of a cylindrical shell-and-tube was examined by Avci et al. [13]. Delgado-Diaz et al. [14] studied how to compare compactness and heat transfer performance for latent heat energy storage (LHES) modules with different designs. Li et al. [15] observed the melting of phase change material inside a horizontal annular space using numerically simulation as well as optimizing.

Although there are notable advantages in PCMs working as TES such as their high storage efficiency and moderately constant temperature between charging and discharging are apparent. However, a crucial disadvantage of PCMs' is their low thermal conductivity which prolongs the melting or solidification time. Farid et al. [16] observed this drawback of PCM in different applications. Many concepts and technologies are proposed as thermal conductivity enhancers (TCE). Two types of improving techniques can be classified. The firstly category of TCE involves establishing extensive surfaces like fins and graphite-compound [17-19] and metal foam [20,21]. The utilization of free-form enhancers, the other approach entails nanoparticles [21,22]. Dhaidan et al. [23] scrutinized the melting of n-octa decane containing $\mathrm{CuO}$ nanoparticle solutions in a square enclosed by using the finite element method to resolve the coupled continuity, velocity, and temperature governing equations. Their findings show that enhancing the thermal conductivity of the PCM/nanoparticle component, improving the composite temperature and growing the heat transport rate are all significant impacts of nano particle processing. Atal et al. [24] described numerical simulations to suggest that by using a conduct matrix including PCM material decreased the time taken for a processing cycle and that using metallic foam with lower porosity minimized the cycle even further due to increased total thermal conductivity. 
The impact of introducing nano-particles to the PCM has been explored by a number of scientists. Murshed et al. [25] presented in their significant analysis that nanofluids demonstrate significant progress in meeting the cooling requirements of higher heat generated electronic equipment due to their greater thermal properties and various advantages. Afif [26] reviewed the impact of utilizing phase transition materials to reduce the heating/cooling loads for structures through a numerical approach utilizing Comsol technology. It was suggested that displacing particles of strongly conducting materials through PCMs would increase the solidification level of PCMs. Particle diffusion was used in many experiments to improve PCM solidification. He et al. [27] studied thermophysical properties of nanofluids as phase-change material in low temperature storage. Chaichan et al. [28] examined the increasing thermal conductivity of paraffin wax by incorporating nanoparticles and employing two tiny-sized forms of Aluminum particles $\left(\mathrm{Al}_{2} \mathrm{O}_{3}\right)$ and $\mathrm{TiO}_{2}$ particles. Belessiotis et al. [29] provided a form balanced paraffin/ $/ \mathrm{SiO}_{2}$ hybrid $\mathrm{PCM}$ for using LHS through chemical absorption process and then utilizing to encapsulate paraffin wax, using much distinct paraffin to $\mathrm{SiO}_{2}$ formulation ratios. Parsazadah et al. [30] studied the effect of nonmaterial on HTF and PCM in a shell and tube TES model for CSP engineering. Fawziea et al. [31] provided the consequences of applying nano to paraffin wax, concluding that paraffin wax responds well to the addition of nano-particles. Motahar et al. [32] assessed the heat distribution properties of n-octadcane solidified with different weights of $\mathrm{TiO}_{2}$ nano-particles in a rectangular framework. Sharma et al. [33] proposed a combination of passively cooling mechanism for building-integrated photovoltaic that included micro fins, PCM, and nanoparticle improved PCM (n-PCM). Yazici et al. [34] measured energy storage efficiency with total melting time of $\mathrm{PCM} /$ graphite matrix in a tube-in-shell.

From a close review of related literature, it comes to know that most of the existing studies involve square, rectangle or cylindrical designs. It is noteworthy to consider trapezoidal design for latent heat thermal-energy storage method (LHTEM). This is interesting geometry to fit in buildings, motor vehicles and other gadgets such as computers and mobile phones where energy consumption is on rise. The major objective remains to save available heat energy. Rubitherm-35 (RT-35) is a chemically inert PCM with no super cooling [35]. Cobalt oxide nanoparticles find common applications such as solar energy absorbers and have improved thermal conductivity.

\section{Physical Model}

A trapezoidal box of aluminum with parallel sides $150 \& 180 \mathrm{~mm}$ and of altitude $41.5 \mathrm{~mm}$ is considered. The heater dimensions are $150 \mathrm{~mm} \times 42 \mathrm{~mm}$ and the heat rate is 48 watts. The remaining boundary is adiabatic. Paraffin (Rubitherm-RT35) is used as PCM. Fig. 1a exhibits empty structure using Solidworks. Fig. 1 b presents design geometry in Comsol Multiphysics. The lab set up is portrayed in Fig. 2. 


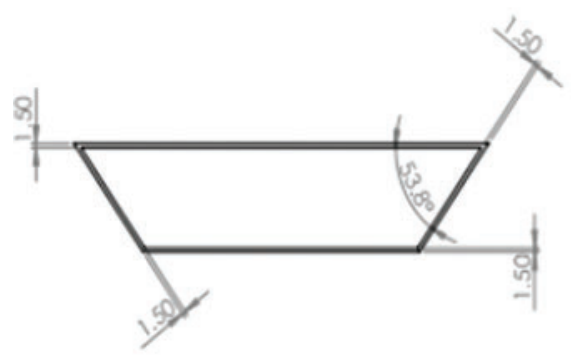

(a)

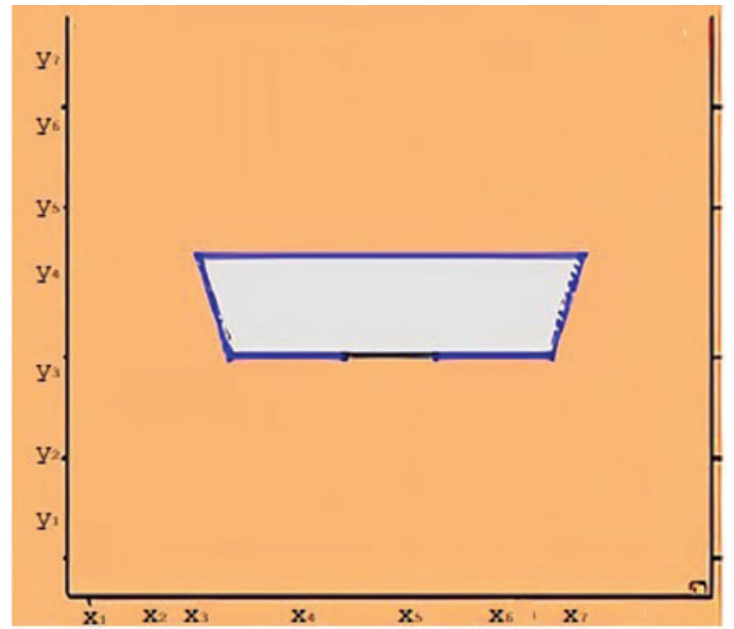

(b)

Figure 1: (a) The geometrical designs (b) The comsol geometry

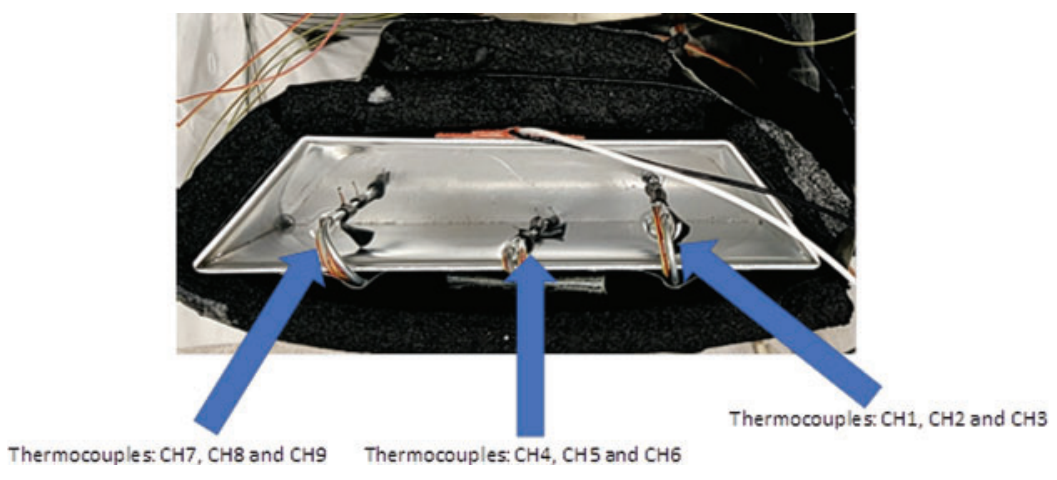

Figure 2: The experimental configuration

\section{Governing Equations}

The physical properties of PCM are temperature dependent. The volume fraction resulting from phase change and viscous dissipation are negligible. Both the conduction and convection heat transformation take place. The governing equations, by following [36] are:

Continuity equation

$\frac{\partial \rho}{\partial t}+\nabla \cdot(\rho U)=0$

Momentum equation

$\frac{\partial(\rho U)}{\partial t}+\nabla \cdot(\rho U U)=-\nabla \cdot P+\rho g+\nabla \tau+F$

Energy equation

$\frac{\partial(\rho H)}{\partial t}+\nabla \cdot(\rho U H)=\nabla \cdot(K \nabla T)+S$ 
The latent heat content signified by the $L$ in the terms of latent heat (LH) of PCM is: $\nabla H=\beta L$

Here $\beta$ stands for the fluid fraction to be described by [37] as given below:

$\beta=0$ if $T<T_{\text {solids }}$

$\beta=1$ if $T>T_{\text {liquids }}$

$\beta=\frac{T-T_{\text {solids }}}{T_{\text {liquids }}-T_{\text {solids }}} \quad$ if $T_{\text {solids }}<T<T_{\text {liquids }}$

The Eqs. (3) and (4) provide iterative solution for temperature.

The mushy region is treated as porous medium for enthalpy-porosity technique.

Porosity is zero for fully solidified region; hence zero velocity is resulted in these regions.

\section{Properties of Nano Particles}

The doping of paraffin wax with Cobalt oxide $\mathrm{Co}_{3} \mathrm{O}_{4}$ nanoparticles has been made to augment the thermal conductivity of PCM. The dissimilarity in solids and fluids temperatures marks the change from solid to fluid phases when PCM melts.

The latent heat, heat capacity and density of nano PCM are identified as [37]:

$$
\begin{aligned}
L_{n p c m} & =\frac{(1-\phi)(\rho L)_{p c m}}{\rho_{\text {npcm }}} \\
C_{p_{\text {npcm }}} & =\frac{\phi\left(\rho C_{p}\right)_{n p}+(1-\phi)\left(\rho C_{p}\right)_{p c m}}{\rho_{\text {npcm }}}
\end{aligned}
$$

$\rho_{\text {npcm }}=\phi \rho_{n p}+\phi \rho_{p c m}$

The volume fraction of nano particles is $\phi$.

The viscosity and thermal conductivity of nano PCM are:

$\mu_{\text {npcm }}=0.983 e^{(12.958 \phi)}$

$$
\begin{aligned}
K_{n p c m}= & \frac{K_{n p}+2 K_{p c m}-2\left(K_{p c m}-K_{n p}\right) \phi}{K_{n p}+2 K_{p c m}+2\left(K_{p c m}-K_{n p}\right) \phi} K_{p c m} \\
& +5 \times 10^{4} \beta_{k} \varsigma \phi C \rho_{p c m} C_{p_{p c m}} \sqrt{\frac{B T}{\rho_{n p} d_{n p} f(T, \phi)}}
\end{aligned}
$$

Physical Properties of cobalt oxide $\left(\mathrm{Co}_{3} \mathrm{O}_{4}\right)$ nanoparticles
Density
$6.11 \mathrm{~g} / \mathrm{cm}^{3}$
Melting Point
$895^{\circ} \mathrm{C}$ 


\section{Properties of Paraffin RT 35 (PCM)}

The industrial PCM utilized in the investigation was paraffin RT-35, with a phase modifying temperature of about $35^{\circ} \mathrm{C}$. All thermal features (TF) of the RT-35 are obtainable in Table 1. Features for RT-line: -higher heat energy storage capability-thermal storage and release take place at relatively constant temperatures-no super cooling consequence, chemically inert-long life product, with stable efficiency throughout the phase change cycles-melting temperature range between $-9^{\circ} \mathrm{C}$ and $10^{\circ} \mathrm{C}$.

Table 1: PCM RT-35 properties [38]

\begin{tabular}{lll}
\hline Material property & Value & Unit \\
\hline Heat storage capacity & 160 & $\mathrm{~K} \mathrm{~J} / \mathrm{kg}$ \\
Heat conductivity & 0.2 & $\mathrm{~W} / \mathrm{mK}$ \\
Melting-area & $29-36$, Main peak 33 & ${ }^{\circ} \mathrm{C}$ \\
Congealing-area & $36-31$, Main peak 35 & ${ }^{\circ} \mathrm{C}$ \\
Specific heat capacity & 2 & $\mathrm{~kJ} / \mathrm{kgK}$ \\
Density solid $\left(\right.$ at $\left.15^{\circ} \mathrm{C}\right)$ & 0.86 & $\mathrm{~kg} / 1$ \\
Density-liquid (at $\left.45^{\circ} \mathrm{C}\right)$ & 0.77 & $\mathrm{~kg} / 1$ \\
Combination of latent and & 45 & $\mathrm{Wh} / \mathrm{kg}$ \\
sensible heat in a & & \\
temperature range of $26^{\circ} \mathrm{C}$ & & \\
to $41^{\circ} \mathrm{C}$ & 65 & ${ }^{\circ} \mathrm{C}$ \\
Max. operation & & \\
temperature & 167 & ${ }^{\circ} \mathrm{C}$ \\
Flashpoint & 12.5 & $\%$ \\
Volume expansion & & \\
\hline
\end{tabular}

\section{Results and Discussion}

Observations for melting of PCM are made after various time intervals. Representative outcomes are described below to understand the conduction convection role for phase change of RT-35 at uniform temperature. The Figs. 3a-3d illustrate the initial melting behavior of the pure PCM after 325 (s). The photograph of the upper observation of the experimental set up in Fig. $3 a$ indicates the starting of melting at the hot bottom side. The melting pattern is more vivid in the colored view from simulation for the same time period as depicted in Fig. 3b. The Fig. 3c delineates the limit of solid PCM and Fig. 3d presents the melting contour. The initial time for melt start is surely lengthy because of low thermal conductivity. After that Figs. 4a$4 \mathrm{~d}$ to $5 \mathrm{a}-5 \mathrm{~d}$ exhibit successive phase transformation of PCM from solid to liquid state after the time intervals 750 (s) and 1500 (s). The melting is slowly increasing whereas the conduction dominates. The photographs are captured after 2500 (s), 3000 (s) and 3750 (s) and exhibited respectively in Figs. $5 a-5 d, 6 a-6 d$ and $7 a-7 d$. In these snaps, the melt processes seems faster and most of the PCM is transformed in to liquid state. Here the convection has developed to join in hand with conduction. Thus the melting seems faster as time passes. Finally, Figs. $8 \mathrm{a}-8 \mathrm{~d}$ portray the total melt after 4500 (s). It is to explain that in the beginning, the melting started due to heat conduction which was stronger at the bottom side. The thermal conduction also expanded gradually due to other sides of the trapezium. With the passage of time the thermal convection is identified to play its role and the melting of solid PCM is continued till total melt is yielded 
after sufficient time length of 4500 (s). It is to mention that the temperature of liquid form of PCM remained almost close to a constant value during this time period and a large amount of heat energy is captured by the PCM mass as latent heat.

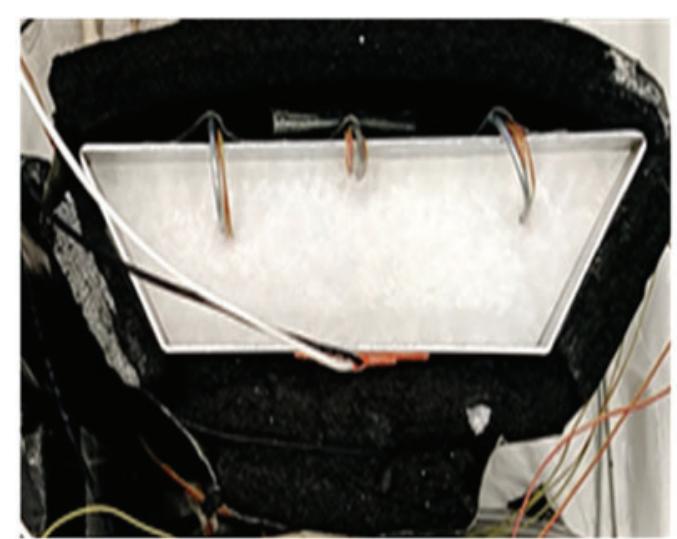

(a)

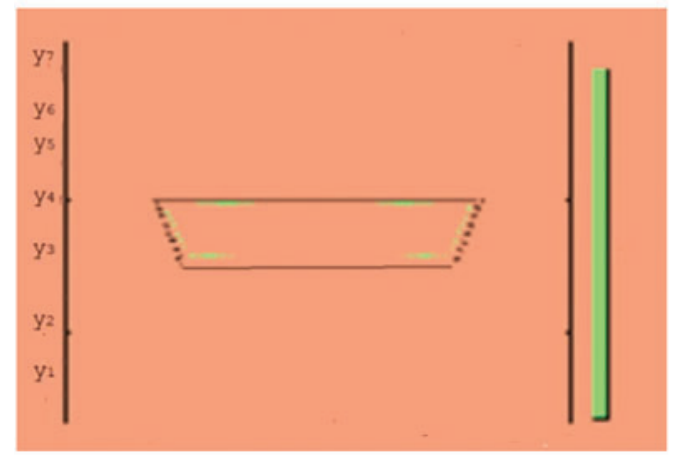

(c)

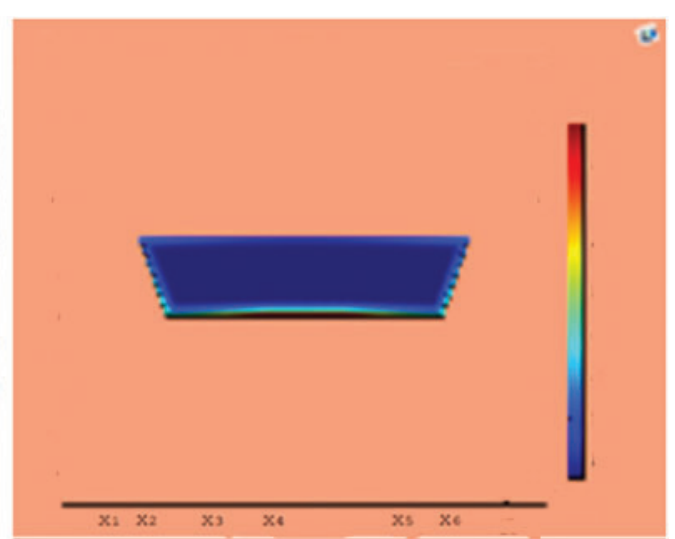

(b)

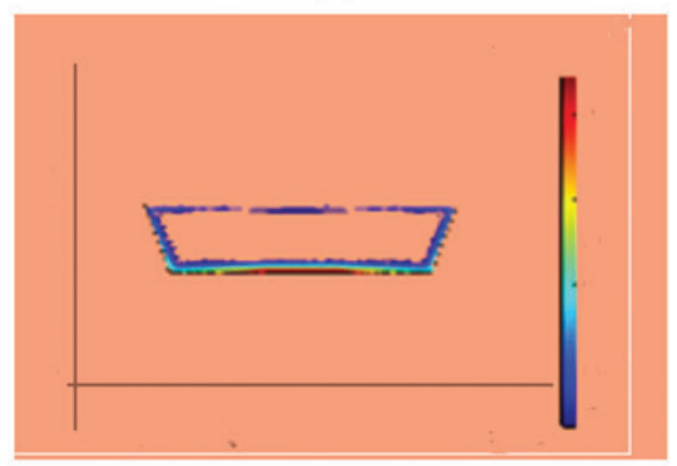

(d)

Figure 3: PCM melt-front after 325 (s) (a) lab observation (b) colored view from simulation (c) limit of solid PCM (d) melting contour

However, the long time for total melt signifies the low thermal conductivity of PCM as remarked in [23]. Enhancement in thermal conductivity of PCM can be attained by harnessing Comsol environment with mixing of nano entities of cobalt oxide $\mathrm{Co}_{3} \mathrm{O}_{4}$ in paraffin PCM that accelerated the melting procedure. Fig. 9 exhibits the starting of melting of PCM till first 150 (s). Figs. 10-12 demonstrate the progressive melting fronts after the time bands of 750 (s), 1500 (s), and 3000 (s). Melting on the top side convinces that convection is dominating. PCM has melted sufficiently near the boundaries due to conduction. The early initiation of melting and notable short time for total melt of the PCM with extension of nano entities convinced that procedure for improvement of thermal conduction is effective for early charging of the PCM thermal energy storage design. 


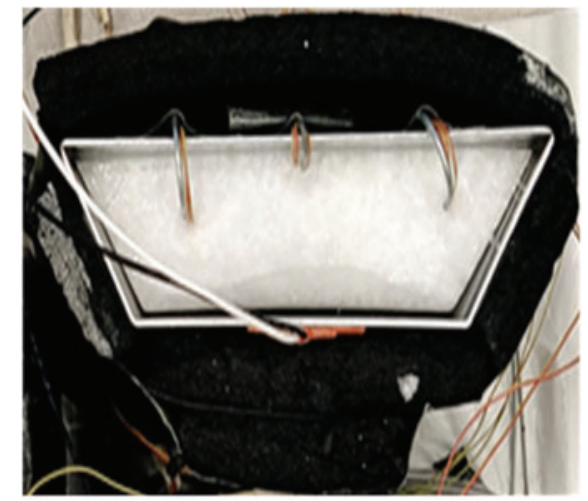

(a)

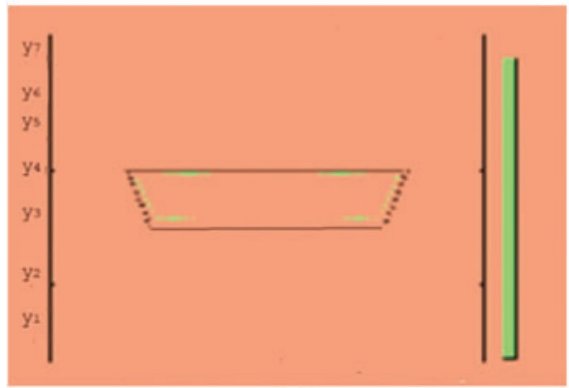

(c)

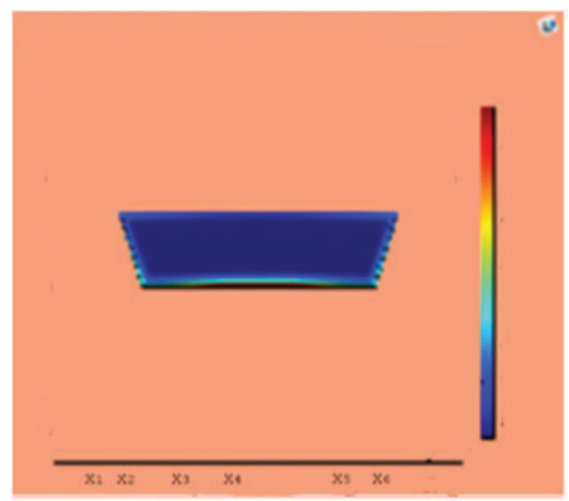

(b)

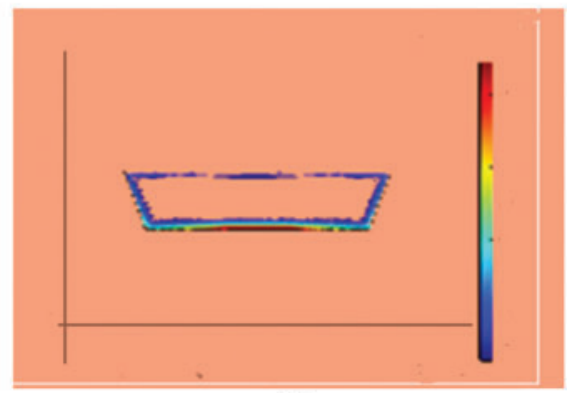

(d)

Figure 4: PCM melt-front after 750 (s) (a) lab observation, (b) colored view from simulation (c) limit of solid PCM (d) melting contour

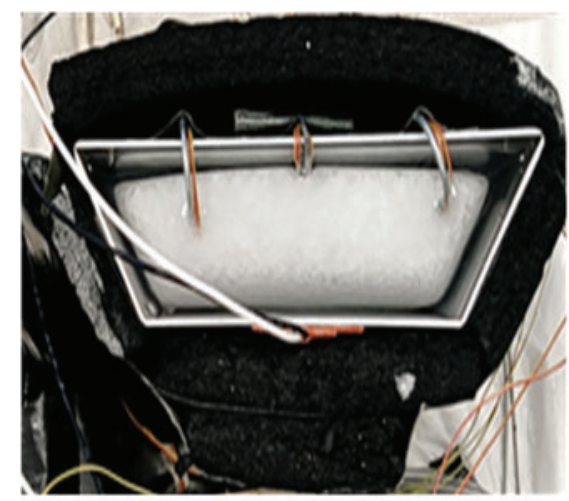

(a)

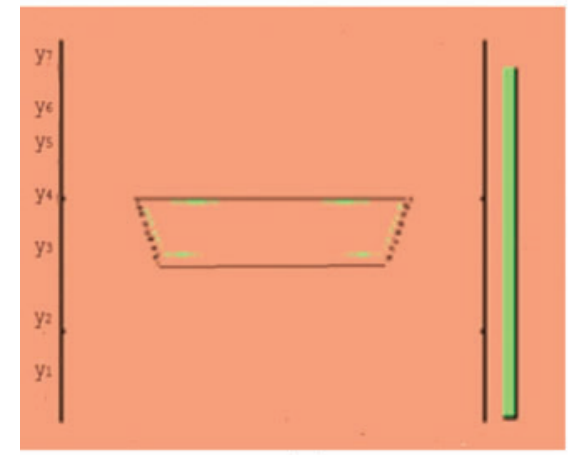

(c)

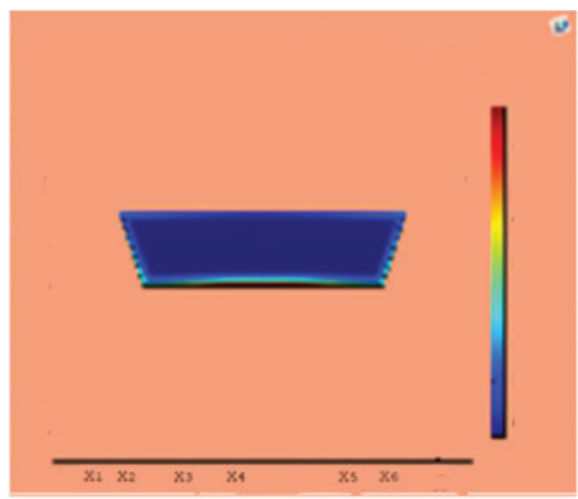

(b)

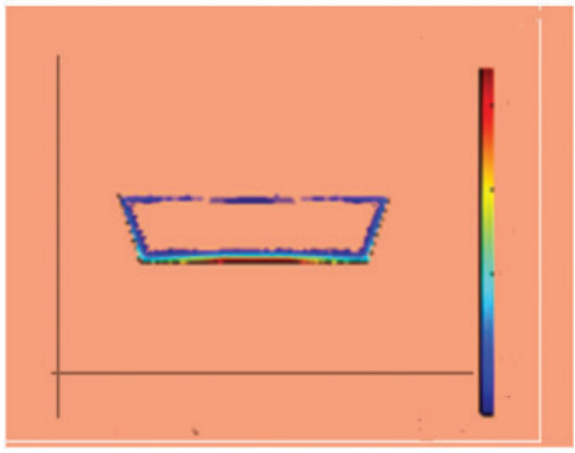

(d)

Figure 5: PCM melt-front after 1500 (s) (a) lab observation, (b) colored view from simulation (c) limit of solid PCM (d) melting contour 


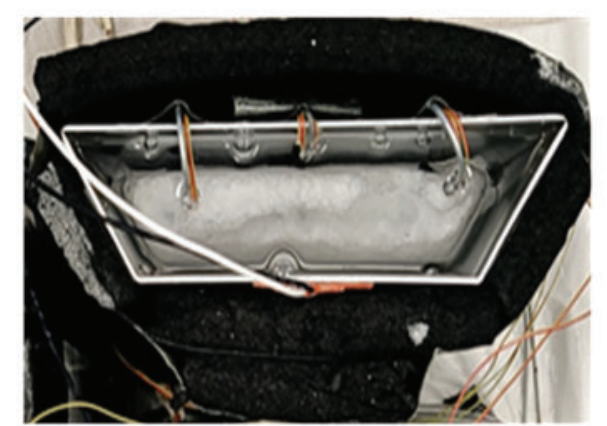

(a)

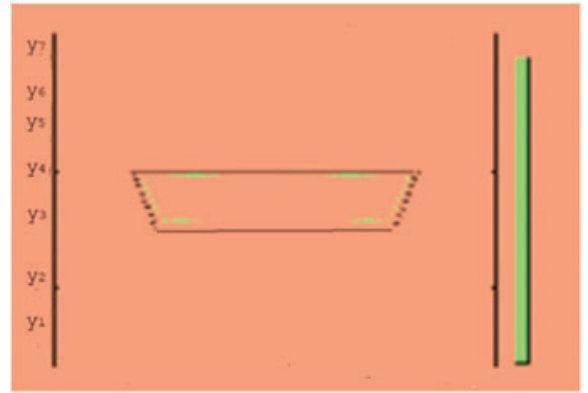

(c)

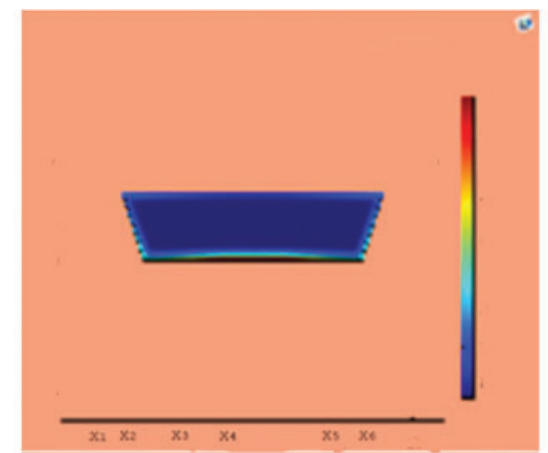

(b)

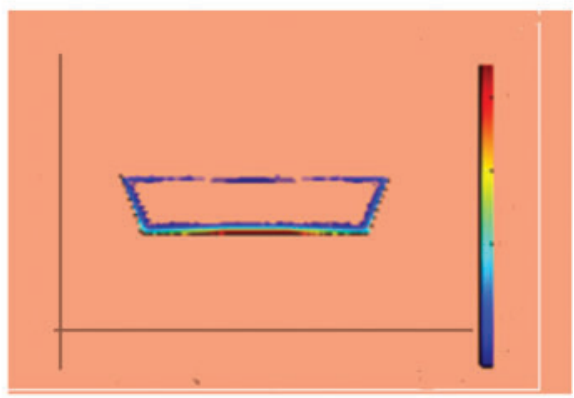

(d)

Figure 6: PCM melt-front after 2500 (s) (a) lab observation, (b) colored view from simulation (c) limit of solid PCM (d) melting contour

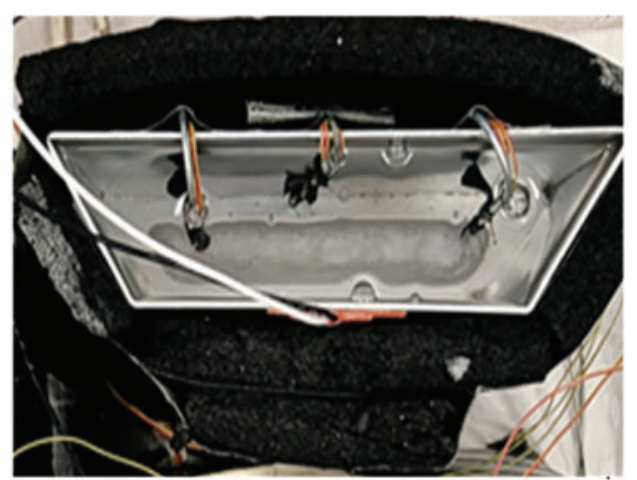

(a)

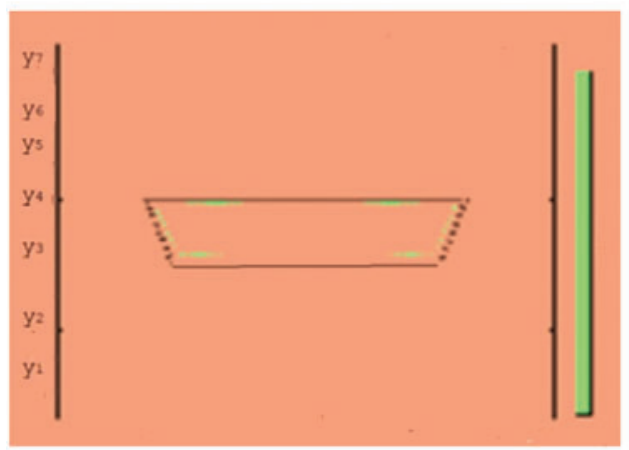

(c)

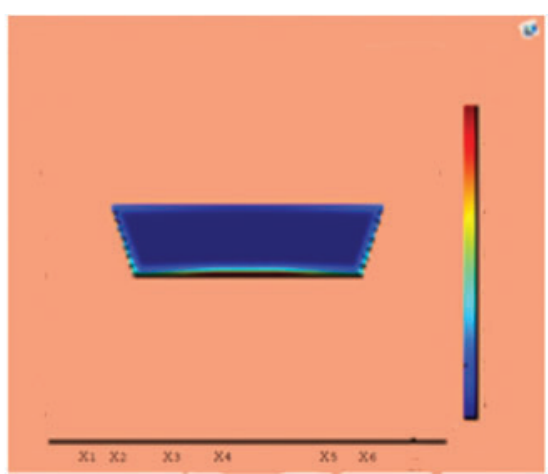

(b)

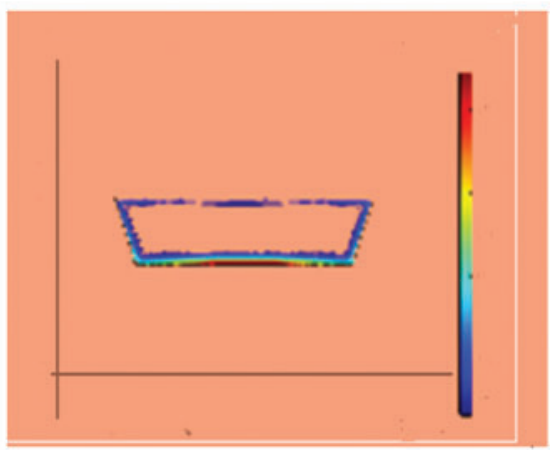

(d)

Figure 7: PCM melt-front after 3750 (s) (a) lab observation, (b) colored view from simulation (c) limit of solid PCM (d) melting contour 


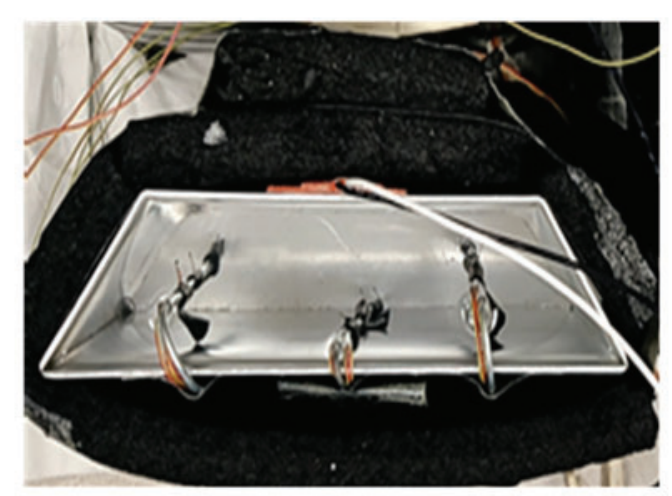

(a)

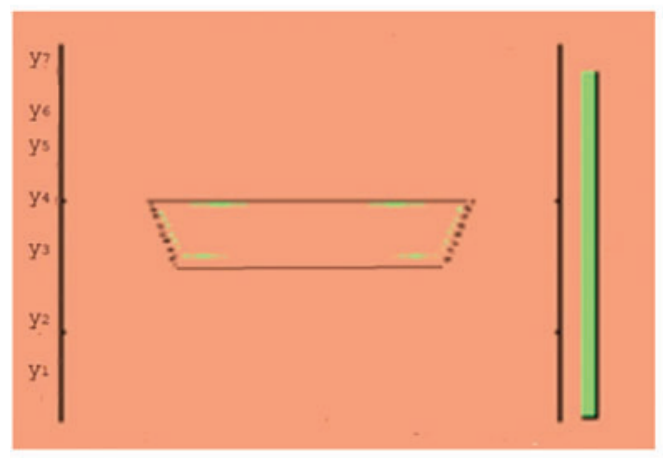

(c)

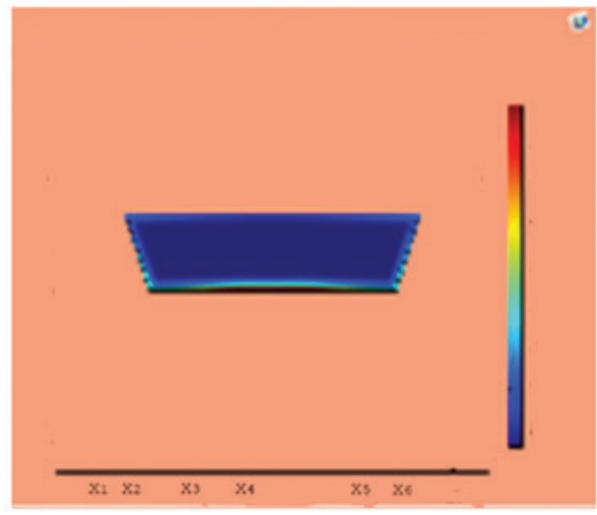

(b)

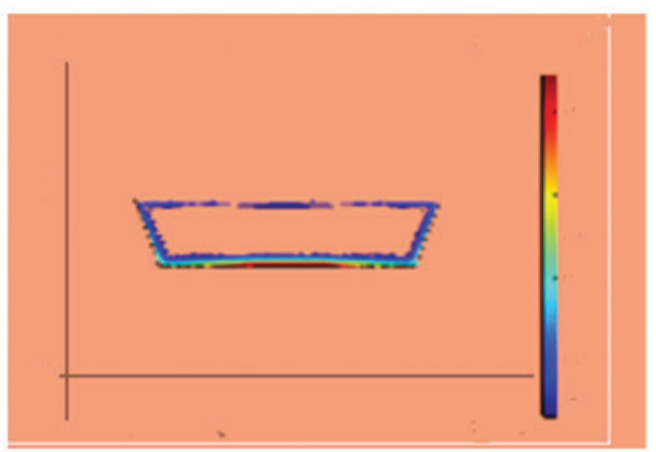

(d)

Figure 8: PCM melt-front after 4500 (s) (a) lab observation, (b) colored view from simulation (c) limit of solid PCM (d) melting contour

\section{Graphical Representation}

This section presents snapshots and computational graphical patterns for phase transformation of the bounded PCM for various time lapses as explained in Section 6 above. Each of the Figs. 1-8, from initiation of melting to total melt of pure PCM consists of four sketches where Part (a) depicts photograph of lab experiment, Part (b) pertains to Comsol simulation, Part (c) exhibit limit of remaining solid PCM and Part (d) delineates melting contour. In Figs. 9-12, the fast melting output of the PCM mixed with nanomaterial for various time periods is exhibited in Part (a)'s for solid fraction and in Part (b)'s for simulated outcome of melt front. 


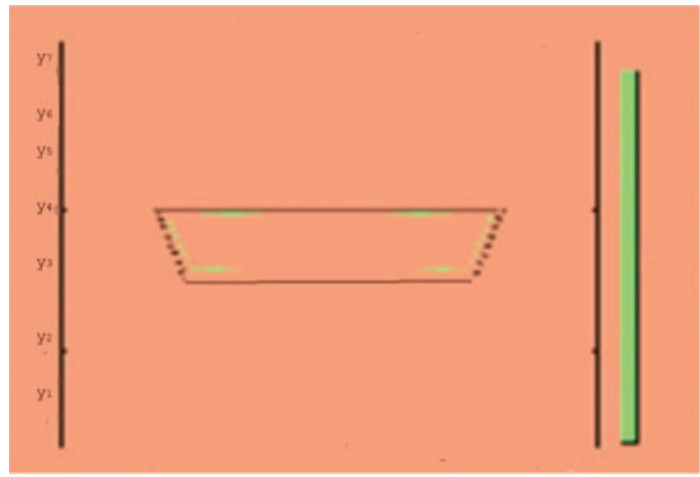

(a)

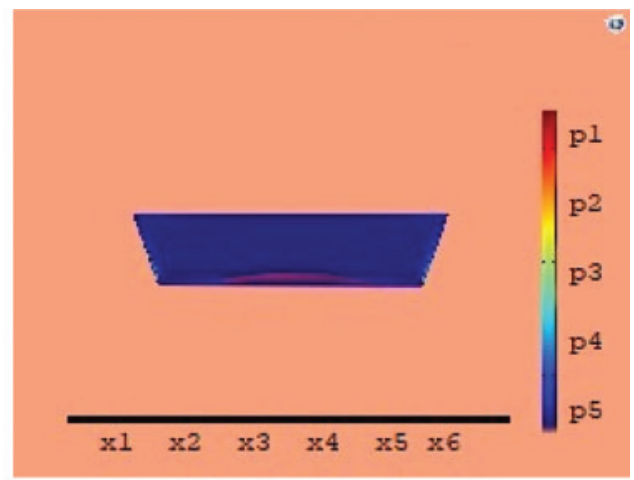

(b)

Figure 9: Melting of wax with nano particles after 150 (s) (a) limit of solid PCM (b) colored view from simulation

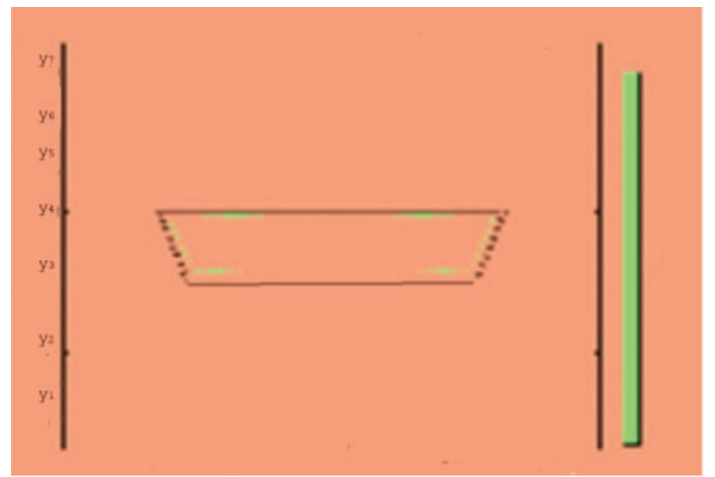

(a)

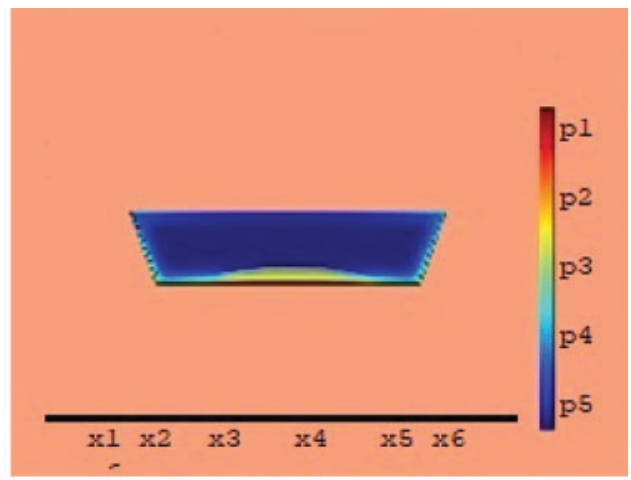

(b)

Figure 10: Melting of wax with nano particles after 750 (s) (a) limit of solid PCM (b) colored view from simulation

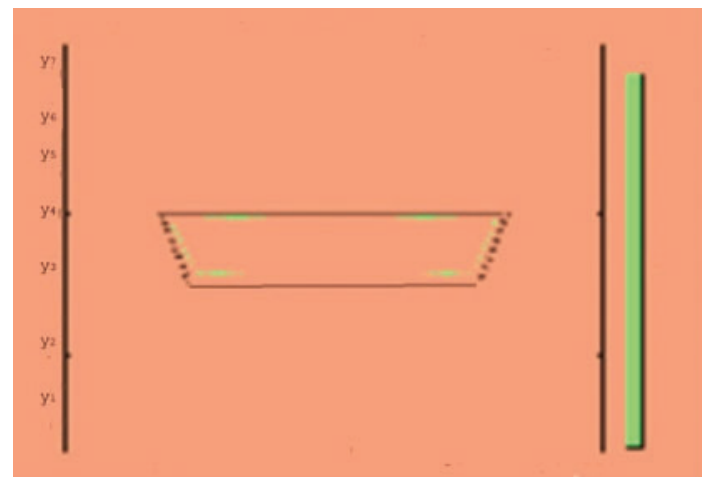

(a)

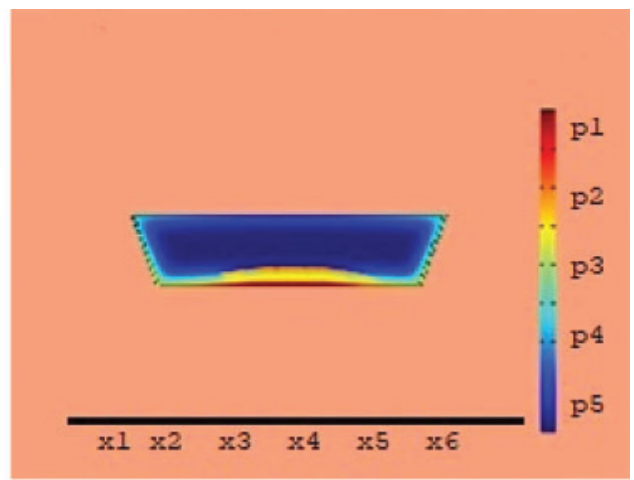

(b)

Figure 11: Melting of wax with nano particles after 1500 (s) (a) limit of solid PCM (b) colored view from simulation 


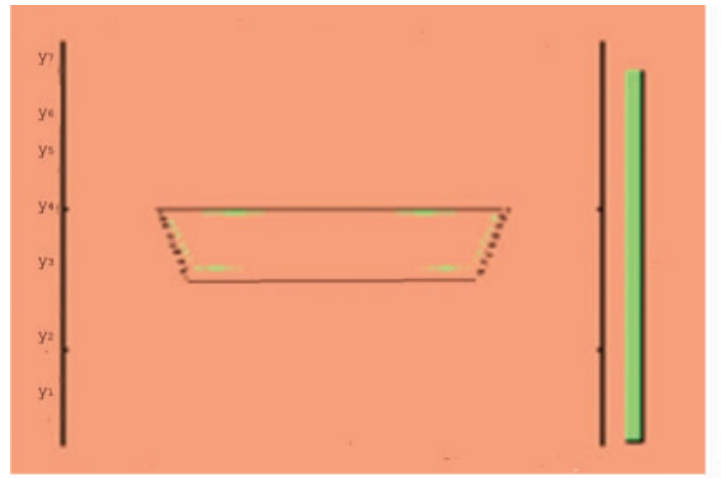

(a)

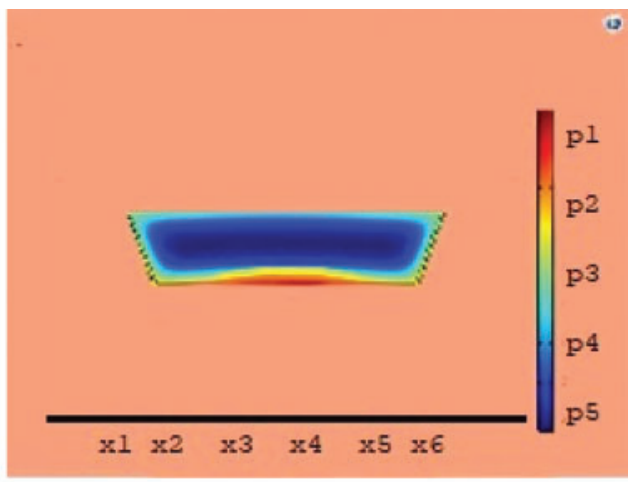

(b)

Figure 12: Melting of wax with nano particles after 3000 (s) (a) limit of solid PCM (b) colored view from simulation

\section{Conclusion}

A thermal energy storage device in trapezoidal shape is studied by using RT-35 as phase change material (PCM). Three different cases for thermal conductivity are considered for PCM only and PCM with nano particles inclusion. The melting of PCM continued over a considerable time length for a close to uniform temperature. However, the charging time for thermal conductivity enhanced case is notably shorter than that for the pure PCM case. The time duration for total melt front in case of PCM is noted to be 4500 (s) and it is 3000 (s) for the case of nano entity mix. There seemed a 33\% less time length for phase transform from solid to liquids form when nano particles are mixed in PCM. In the meanwhile, sufficient amount of heat energy is captured as latent heat. The potential use of PCMs as latent storage media covers renewable energy as well as temperature control of electronic devices and buildings. There is serious short coming in this research field to avail efficient PCMs and effective characteristics of LHS. The extension to this study will address fin augmentation and nano inclusion of PCM melting. Further solidification cycles can be managed and forced convection for a range of Nusselt number will contribute to desired thermal transportation.

Funding Statement: The authors received no specific funding for this study.

Conflicts of Interest: The authors declare that they have no conflicts of interest to report regarding the present study.

\section{References}

1. Kenisarin, M., Mahkamov, K. (2007). Solar energy storage using phase change materials. Renewable and Sustainable Energy Reviews, 11, 1913-1965. DOI 10.1016/j.rser.2006.05.005.

2. Zheng, L., Zhang, W., Liang, F., Lin, S., Jin, X. Y. (2017). Experimental studies of phase change and microencapsulated phase change materials in a cold storage/transportation system with solar driven cooling cycle. Energies, 10, 1867. DOI 10.3390/en10111867.

3. Childs, K., Stovall, T. (2012). Use of phase change material in a building wall assembly: A case study of technical potential in two climates. Second International High Performance Buildings Conference, http://docs.lib.purdue.edu/ihpbc/58.

4. Pielichowska, K., Pielichowski, K. (2014). Phase change materials for thermal energy storage. Progress in Materials Science, 65, 67-123. DOI 10.1016/j.pmatsci.2014.03.005. 
5. Sharma, A., Tyagi, V. V., Chen, C. R., Buddhi, D. (2009). Review on thermal energy storage with phase change materials and applications. Renewable and Sustainable Energy Reviews, 13(2), 318-345. DOI 10.1016/j.rser.2007.10.005.

6. Bayón, R. (2021). Advanced phase change materials for thermal storage. Applied Science, 11, 1390. DOI 10.3390/app11041390.

7. Mao, Q., Liu, N., Peng, L. (2019). Numerical investigations on charging/discharging performance of a novel truncated cone thermal energy storage tank on a concentrated solar power system. International Journal of Photo Energy, 2019, 17. DOI 10.1155/2019/1609234.

8. Ramakrishnan, S. (2015). A novel paraffin/expanded perlite composite phase change material for prevention of PCM leakage in cementitious composites. Applied Energy, 157, 85-94. DOI 10.1016/j.apenergy.2015.08.019.

9. Basit, R., Li, X., Huang, Z., Zhou, Q. (2020). Heat transfer studies of arrays of prolate particles in gas-solid flows. Mathematical Problems in Engineering, 2020, 12. DOI 10.1155/2020/6639172.

10. Ferrer, G. (2017). New proposed methodology for specific heat capacity determination of materials for thermal energy storage (TES) by DSC. Journal of Energy Storage, 11, 1-6.

11. Wu, Y., Tang, Y., Li, Z., Ding, X., Yuan, W. et al. (2016). Experimental investigation of a PCM-HP heat sink on its thermal performance and anti-thermal-shock capacity for high-power LEDs. Applied Thermal Engineering, 108, 192-203. DOI 10.1016/j.applthermaleng.2016.07.127.

12. Zsembinszki, G., Fernández, A. G., Cabeza, L. F. (2020). Selection of the appropriate phase change material for two innovative compact energy storage systems in residential buildings. Applied Sciences, 10, 2116. DOI 10.3390/app10062116.

13. Avci, M., Yazici, M. Y. (2013). Experimental study of thermal energy storage characteristics of a paraffin in a horizontal tube-in-shell storage unit. Energy Conversion and Management, 73, 271-277. DOI 10.1016/j.enconman.2013.04.030.

14. Delgado-Diaz, W., Stamatiou, A., Maranda, S., Waser, R., Worlitschek, J. (2020). Comparison of heat transfer enhancement techniques in latent heat storage. Applied Sciences, 10, 5519. DOI 10.3390/app10165519.

15. Li, S. W., Chen, Y., Sun, Z. Q. (2017). Numerical simulation and optimization of melting process of phase change material inside horizontal annulus. Energies, 10, 1249. DOI 10.3390/en10091249.

16. Farid, M. M., Khudhair, A. M., Razack, S. A. K., Al-Hallaj, S. (2004). A review on phase change energy storage: Materials and applications. Energy Conversion and Management, 45, 1597-1615. DOI 10.1016/j.enconman.2003.09.015.

17. Zhang, Y., Faghr, A. (1996). Heat transfer enhancement in latent heat thermal energy storage system by using the internally finned tube. Heat Mass Transfer, 39, 3165-3173. DOI 10.1016/0017-9310(95)00402-5.

18. Sharikian, V., Ziskind, G., Letan, R. (2005). Numerical investigation of a PCM-based heat sink with internal fins. Heat Mass Transfer, 48, 3689-3706. DOI 10.1016/j.ijheatmasstransfer.2004.10.042.

19. Mat, S., Al-Abidi, A. A., Sopian, K., Sularman, M. Y., Mohammad, A. T. (2013). Enhance heat transfer for PCM melting in triplex tube with internal-external fins. Energy Conversion and Management, 74, 223-236. DOI 10.1016/j.enconman.2013.05.003.

20. Zhu, F., Zhang, C., Gong, X. (2017). Numerical analysis on the energy storage efficiency of phase change material embedded in finned metal foam with graded porosity. Applied Thermal Engineering, 123, 256-265. DOI 10.1016/j.applthermaleng.2017.05.075.

21. Yang, X., Lu, Z., Bai, Q., Zhang, Q., Jin, L. et al. (2017). Thermal performance of a shell-and-tube latent heat thermal energy storage unit: Role of annular fins. Applied Energy, 202, 558-570.

22. Bechiri, M., Mansouri, K. (2016). Analytical study of heat generation effects on melting and solidification of nano-enhanced PCM inside a horizontal cylindrical enclosure. Applied Thermal Engineering, 104, 779-790. DOI 10.1016/j.apenergy.2017.05.007.

23. Dhaidan, N. S., Khodadadi, J. M., Al-Hattab, T. A., Al-Mashat, S. M. (2013). Experimental and numerical investigation of melting of phase change material/nanoparticle suspensions in a square container subjected to a constant heat flux. International Journal of Heat and Mass Transfer, 66, 672-683. DOI 10.1016/J.APPLTHERMALENG.2016.05.105. 
24. Atal, A., Wang, Y., Harsha, M., Sengupta, S. (2016). Effect of porosity of conducting matrix on a phase change energy storage device. International Journal of Heat and Mass Transfer, 93, 9-16. DOI 10.1016/j.ijheatmasstransfer.2015.09.033.

25. Murshed, S. M. S., Nieto de Castro, C. A. (2017). A critical review of traditional and emerging techniques and fluids for electronics cooling. Renewable and Sustainable Energy Reviews, 78, 821-833. DOI 10.1016/j.rser.2017.04.112.

26. Afif, H. K. (2012). Solar energy storage in buildings using composite PCM containing nano particles (Master Thesis). University of Jordan, Jordan.

27. He, Q., Wang, S., Tong, M., Liu, Y. (2012). Experimental study on thermophysical properties of nanofluids as phase-change material in low temperature storage. Energy Conversion and Management, 64, 199-205. DOI 10.1088/1757-899X/912/4/042040.

28. Chaichan, M. T., Kamel, H., Shaima, A. N., Al-Ajeely, M. (2015). Thermal conductivity enhancement by using nano-material in phase change material for latent heat thermal energy storage systems. Saussurea, $5(6), 48-55$.

29. Belessiotis, G. V., Papadokostaki, K. G., Favvas, E. P., Efthimiadou, E. K., Karellas, S. (2018). Preparation and investigation of distinct and shape stable paraffin $/ \mathrm{SiO}_{2}$ composite PCM nano spheres. Energy Conversion and Management, 168, 382-394. DOI 10.1016/j.enconman.2018.04.059.

30. Parsazadeh, M., Duan, X. (2017). Numerical and statistical study on melting of nanoparticle enhanced phase change material in a shell-and-tube thermal energy storage system. Applied Thermal Engineering, 111, 950-960. DOI 10.1016/j.apenergy.2018.02.052.

31. Fawziea, M. H., Faraj, J. J., Kareem, R. J. (2018). Experimental investigation of adding nano-particles to PCM for heating applications. Journal of Mechanical Engineering and Automation, 8(1), 32-37. DOI 10.5923/j.jmea.20180801.03.

32. Motahar, S., Alemrajabi, A. A., Khodabandeh, R. (2017). Experimental study on solidification process of a phase change material containing $\mathrm{TiO}_{2}$ nanoparticles for thermal energy storage. Energy Conversion and Management, 138, 162-170. DOI 10.1016/j.enconman.2017.01.051.

33. Sharma, L. M., Changb, W., Tahir, A. A., Reddy, K. S., Mallick, T. K. (2017). Nano-enhanced phase change material for thermal management of BICPVS. Applied Energy, 208, 719-733. DOI 10.1016/j.apenergy.2017.09.076.

34. Yazici, M. Y., Saglam, M., Aydin, O., Avci, M. (2021). Thermal energy storage performance of PCM/graphite matrix composite in a tube-in-shell geometry. Thermal Science and Engineering Progress, 23, 100915. DOI 10.1016/j.tsep.2021.100915.

35. Rubitherm Technologies, GmbH, Imhoffweg 6 D-12307. Berlin, Version: 06.08.2018. www.rubitherm.com.

36. Li, S., Chen, Y., Sun, Z. (2017). Numerical simulation and optimization of the melting process of phase change material inside horizontal annulus. Energies, 10, 1249. DOI 10.3390/en10091249.

37. Auriemma, M., Iazzetta, A. (2016). Numerical analysis of melting of paraffin wax with $\mathrm{Al}_{2} \mathrm{O}_{3}, \mathrm{ZnO}$ and $\mathrm{CuO}$ nano particles in rectangular enclosure. Indian Journal of Science and Technology, 9(3), 1-8. DOI 10.17485/ijst/2016/v9i4/72601.

38. Liu, H., Li, S., Chen, Y., Sun, Z. (2014). The melting of phase change material in a cylinder shell with hierarchical heat sink array. Applied Thermal Engineering, 73, 975-983. DOI 10.1016/j.applthermaleng.2014.08.062. 